\title{
Sistem Akses Pintu Berbasis Face Recognition Menggunakan ESP32 Module dan Aplikasi Telegram
}

\author{
Nuraeni ${ }^{1}$, Indah Anggraini ${ }^{2}$, Nurul Isra Humairah $B^{3}$, Indri Pratiwi Ramadhani ${ }^{4}$, Muhammad Sabirin Hadis ${ }^{5 *}$, \\ Muliadi $^{6}$, Nurzaenab $^{7}$ \\ 1,2,3,4,6 Universitas Negeri Makassar, ${ }^{5,7}$ STMIK AKBA \\ ${ }^{1}$ nraeninasiregmail.com, \\ 2indahanggrainiegmail.com, \\ ${ }^{3}$ israhumaira@gmail.com, \\ ${ }^{4}$ indripratiwiegmail.com, \\ ${ }^{6}$ muliadi7404@unm.ac.id, \\ ${ }^{7}$ nurzaenabeakba.ac.id \\ ${ }^{5}$ muhammadsabirinhadislakba.ac.id
}

\begin{abstract}
Abstrak - Kasus pencurian yang terjadi terkadang didukung oleh kelalaian pengguna dalam mengontrol kunci pintu. Beberapa penelitian terkait sistem penguncian pintu berbasis teknologi informasi dan komunikasi telah dikembangkan untuk mengatasi permasalahan tersebut namun membutuhkan biaya yang besar untuk penerapannya. Pada makalah ini telah dibangun sistem penguncian pintu cerdas berbasis pengenalan wajah yang dapat diterapkan dengan biaya yang terjangkau karena menggunakan aplikasi gratis yaitu Telegram untuk memantau dan mengontrol sistem penguncian. Hasil pengujian yang telah diperoleh adalah rata-rata waktu pengiriman data dari ESP32 ke Telegram selama 4,74 detik dan rata-rata waktu pengontrolan dari Telegram ke Relay adalah 0,81 detik. Sistem kunci pintu yang dibangun dapat membantu pengguna untuk memantau dan mengontrol kunci dari jarak jauh dan dengan biaya implementasi yang rendah sehingga kelalaian pengguna dapat diminimalisir.
\end{abstract}

Kata Kunci: Sistem Akses; Sistem Penguncian Pintu; Face Recognition; Internet of Things; Telegram; ESP32 Module;

\section{PENDAHULUAN}

Teknologi saat ini berkembang dengan sangat pesat dan merupakan salah satu bidang yang mempunyai peran penting dalam beberapa aspek kehidupan manusia, termasuk pada bidang security. Saat ini sudah banyak berkembang sebuah sistem pengamananan akses masuk pada sebuah rumah atau ruangan dengan sistem komputer dengan beberapa verifikasi identitas, baik dengan menggunakan kartu [1], password [2][3], smartphone [4] dan sebagainya. Salah satu manfaat dari pengembangan teknologi ini adalah untuk meminimalisir terjadinya tindak kejahatan.

Beberapa faktor yang dapat menyebabkan terjadi pencurian di rumah-rumah salah satunya karena sistem keamanan pintu rumah yang tidak terproteksi dengan baik. Kasus pencurian yang terjadi kadang kala didukung dengan adanya kesempatan bukan hanya melibatkan niat dari para pelaku. Kelalaian atau kurang waspadanya calon korban menjadi salah satu penyebab tingginya tingkat kejahatan tindakan pencurian. Hal ini menyebabkan perlu adanya solusi terkait sistem keamanan yang lebih baik. Sistem keamanan tersebut tidak hanya memiliki tingkat keamanan yang baik namun juga dapat dipantu secara online pada setiap aktifitasnya. Kemajuan teknologi saat ini memunculkan suatu inovasi untuk merancang dan membangun suatu sistem akses keamanan berbasis Face Recognition menggunakan modul ESP32 dan Aplikasi Telegram sebagai alat monitoring sistem.

Pada penelitian sebelumnya akses berbasis Face Recognition telah dilakukan oleh Willy Andika Putra et al [5] menggunakan metode Haar-Cascade dan Local Binary Pattern pada Raspberry Pi. Selanjutnya, implementasi Face Recognition menggunakan Raspberry Pi untuk akses ruangan pribadi telah dilakukan oleh Criyus Lesman et al [6]. Pembuatan Smart Home Security menggunakan Face Recognition dengan metode Eigenface berbasis Raspberry Pi dilakukan oleh Rudi Kurniawan et al [7]. Perancangan Door Lock berbasis Face Recognition dengan metoda Eigenfaces menggunakan OpenCV versi 2.4.9 dan Telegram Messenger berbasis Raspberry Pi telah dilakukan oleh Agung Yoke Basuki et al [8], Telegram dapat berjalan sangat baik dengan rata rata pengiriman informasi adalah 3.71 detik. Sistem
Pengamanan Pintu Rumah berbasis Internet of Things (IoT) dengan menggunakan ESP8266 dibangun oleh Arafat et al [9]. M.F Wicaksono et al [10] membangun Smart Home System menggunakan Arduino dan ESP32 Cam untuk mengontrol peralatan rumah tangga serta memonitoring keamanan dalam rumah.

Penelitian yang telah dipaparkan belum ada yang menggunakan ESP32 sebagai pengontrol utama dan objek wajah yang diuji belum spesifik pada kategori tertentu sehingga pada penelitian ini dirancang dan dibangun Sistem Akses Cerdas Berbasis Face Recognition menggunakan modul EPS32 dan Aplikasi Telegram sebagai alat monitoring sistem serta fokus pengujian pada karakter wajah orang Asia. Sistem ini diharapkan dapat meminimalisir terjadinya tindakan pencurian dan pelanggaran akses terhadap lokasi-lokasi yang memiliki akses terbatas.

\section{METODE}

Bagian ini menjelaskan terkait Arsitektur Sistem, Hardware, Software, dan cara kerja sistem serta model pengujian yang dilakukan.

\section{A. Arsitektur Sistem}

Sistem yang dibangun menggunakan EPS32 [11] sebagai pengontrol utama pada lalu lintas data yang terjadi pada sistem. Modul kamera tipe OV2640 [12] digunakan untuk mendeteksi dan mengenali wajah pengguna yang selanjutnya akan dikirim ke aplikasi telegram yang terhubung dengan koneksi Internet. Sistem yang dirancang dilengkapi dengan Buzzer yang berfungsi mengeluarkan suara alarm jika wajah yang terdeteksi bukan pengguna dan juga push button digunakan untuk membuka akses secara manual. Untuk lebih jelasnya model arsitektur yang dibangun dapat dilihat pada Gambar 1. 


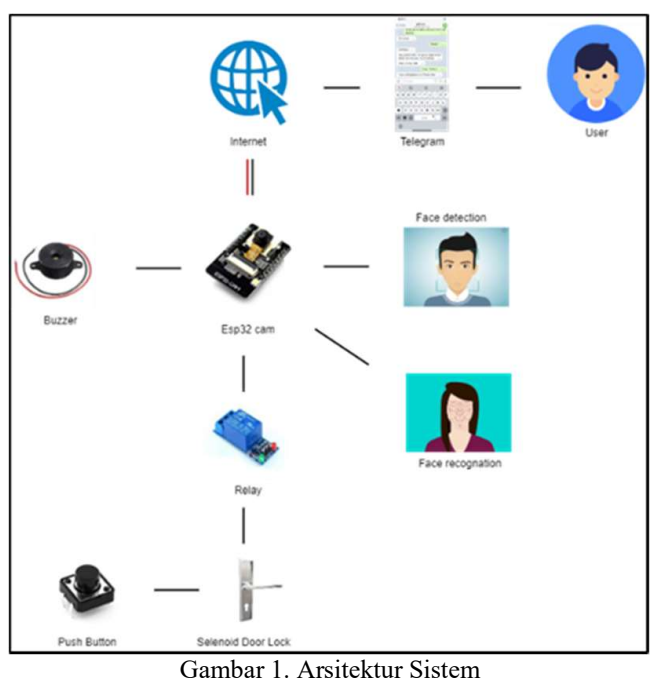

B. Perangkat Keras

Spesifikasi secara detail terkait komponen-komponen perangkat pembangun sistem dapat dilihat pada Tabel 2.

\begin{tabular}{|c|c|c|c|}
\hline No. & Nama Alat & Spesifikasi & Jumlah \\
\hline 1. & ESP32 & $\begin{array}{l}\text { Jumlah pin : } 30 \text { pin } \\
(15 \times 2) ; \text { Chip Op } \\
\text { voltage: } 2.7 \sim 3.6 \text { DC; } \\
\text { Modul Op Voltage : } 5 \mathrm{~V} \\
\text { DC }\end{array}$ & 1 \\
\hline 2. & $\begin{array}{l}\text { Sensor } \\
\text { Kamera } \\
\text { OV2640 }\end{array}$ & $\begin{array}{l}\text { Resolusi kamera: } 2 \\
\text { Megapixel; Konsumsi } \\
\text { energi: } 125 \mathrm{~mW} \text { (for } 15 \\
\text { fps, YUV mode) } 140 \\
\text { mW (for } 15 \mathrm{fps}, \\
\text { compressed mode) } \\
\text { standby: } 600 \mu \mathrm{A}\end{array}$ & 1 \\
\hline 3. & Relay & $\begin{array}{l}\text { 1 Chanel; Tegangan } \\
\text { input : } 5 \mathrm{~V} \text {; Tegangan } \\
\text { output : } 250 \mathrm{~V} / 30 \mathrm{VDC} \\
10 \mathrm{~A}\end{array}$ & 1 \\
\hline 4. & Buzzer & $\begin{array}{l}\text { Tegangan kerja : } 5 \mathrm{~V} \\
\text { DC; Arus max : } 30 \mathrm{~mA} \text {; } \\
\text { Kekuatan suara max: } \\
85 \mathrm{db} / 10 \mathrm{~cm}\end{array}$ & 1 \\
\hline 5. & $\begin{array}{l}\text { Selenoid } \\
\text { Door Lock }\end{array}$ & $\begin{array}{l}\text { Tegangan : 12VDC; } \\
\text { Arus : } 0,35 \mathrm{~A} ; \text { Bentuk } \\
\text { energi : intermittent }\end{array}$ & 1 \\
\hline 6. & Button & $\begin{array}{l}\text { DPST } 4 \text { Pin; Current : } \\
50 \mathrm{~mA} / 12 \text { VDC; Push } \\
\text { on }\end{array}$ & 1 \\
\hline 7. & Baterai & $\begin{array}{l}\text { Tipe : AA; Kapasitas } \\
\text { Batterai : } 1,5 \mathrm{~V} \text {; Berat } \\
\text { Bersih : } 200 \text { gr }\end{array}$ & 4 \\
\hline
\end{tabular}

1) ESP32

ESP32 digunakan sebagai controller pada sistem yang dibangun untuk mengolah data input dari sensor dan memberikan instruksi terhadap perangkat output sesuai dengan kondisi yang dijabarkan oleh perangkat input.

2) Sensor Kamera OV2640

Sensor Kamera OV2640 digunakan untuk mengambil gambar dan pengenalan wajah. Jika wajah yang dimasukkan salah maka ESP32 akan memberikan informasi melalui aplikasi telegram berupa gambar. Pada alat ini dilengkapi tombol yang berfungsi untuk mengaktifkan mode Tamu.

3) Relay

Modul Relay yang digunakan merupakan modul dengan satu channel, berfungsi pemutus otomatis tegangan pada sistem. Pemilihan modul relay karena telah memiliki pin power, ground dan input dimana power dan ground sebagai sumber tegangan dan grounding, pin input disambungkan ke pin digital 14 pada Sensor Kamera OV2640 sebagai pengatur keadaan relay, block terminal untuk actuator dalam hal ini selenoid door lock.

4) Buzzer

Buzzer digunakan sebagai alarm dan akan berbunyi jika Sensor Kamera OV2640 mendapatkan kecocokan ataupun tidak dengan citra wajah yang diambil dengan database yang ada dengan keadaan bunyi yang berbeda. Buzzer dihubungkan ke pin digital 18 dan ground pada Sensor Kamera OV2640.

5) Selenoid Door Lock

Selenoid Door Lock digunakan sebagai actuator sehingga nantinya pintu pada sistem ini dapat terbuka secara otomatis sesuai dengan keadaan relay. Selenoid door lock disambungkan ke block terminal beban relay dengan normaly open. Selenoid Door Lock yang digunakan pada sistem ini digerakkan dengan tegangan $11 \mathrm{~V}$ DC sehingga untuk sumber salah satu kaki dihubungkan pada Baterai dan Sensor Kamera OV2640.

6) Button

Button digunakan untuk menyalurkan tegangan ke Selenoid Door Lock agar membuka pintu. Dikarenakan sistem ini hanya meletakkan kamera pada bagian depan pintu, maka button dipasang pada bagian dalam prototype agar pintu dapat terbuka dari dalam Button disisipkan pada perangkat lunak agar nantinya tidak mengganggu kerja sistem.

7) Baterai

Baterai yang digunakan sebagai sumber tambahan untuk menyuplai Selenoid Door Lock dan Relay dengan spesifikasi 5V dengan arus $500 \mathrm{mAh}$. Tambahan sumber ini digunakan karena sumber listrik dari ESP32 tidak mampu menyuplai sistem secara keseluruhan.

C. Perangkat Lunak

1) Arduino IDE

Program untuk sistem ini menggunakan Arduino Integrated Development Environment (IDE) dimana dalam perancangannya menggunakan driver yang harus dipasang terlebih dahulu, hal ini bertujuan untuk menghubungkan Sensor Kamera OV2640. Tahapannya sebagai berikut:

a. Membuka halaman kerja program arduino menu file, selanjutnya ke preference, kemudian memasukkan alamat web di references bertujuan agar board ESP32 terinstal di aplikasi arduino.

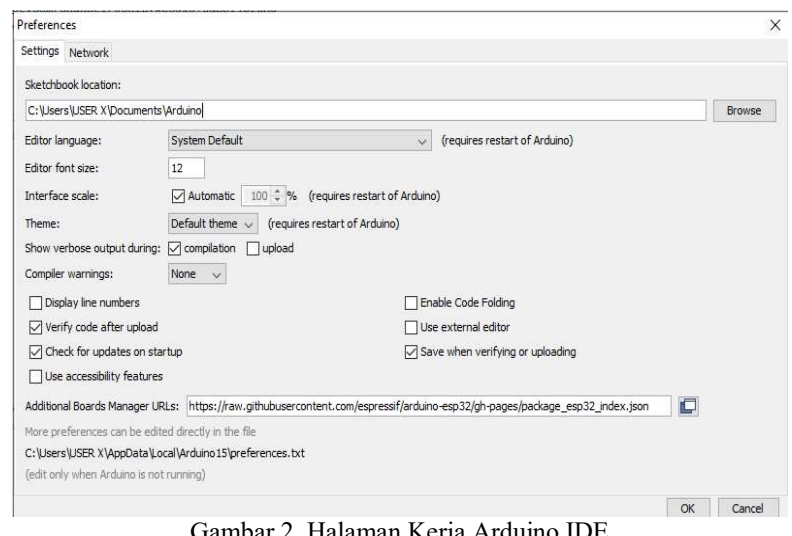

Gambar 2. Halaman Kerja Arduino IDE 
b. Setelah Arduino IDE terpasang, selanjutnya masuk ke menu tool pilih board selanjutnya pilih board manager dan klik ok. Ketik ESP32 pada menu pencarian selanjutnya pasang board ESP32 pada Arduino IDE.

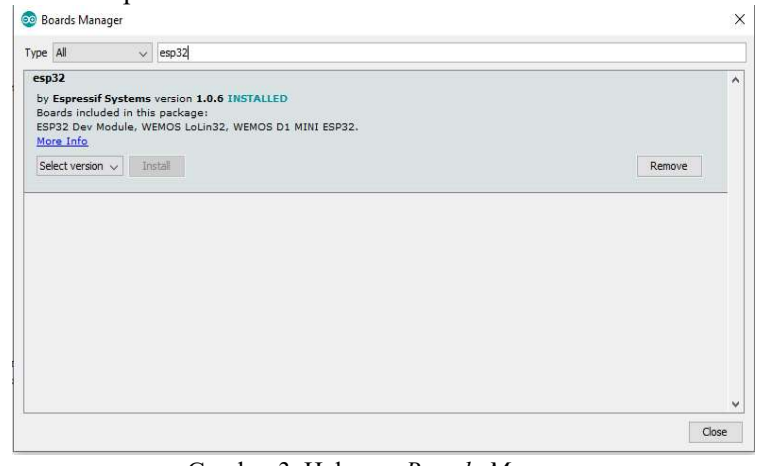

2) Telegram

Gambar 3. Halaman Boards Manager

Dalam penelitian ini Telegram digunakan sebagai pemberi notifikasi ke pemilik rumah tentang adanya wajah yang tidak dikenali berada di depan pintu baik dalam bentuk teks maupun citra wajah orang yang tidak dikenali tersebut. Telegram merupakan aplikasi gratis yang dapat diunduh di berbagai basis gadget selama aplikasi tersebut terpasang. Pengembang Telegram juga menyediakan Application Programming Interface (API) yang dapat diprogram dengan berbagai bahasa pemrograman salah satunya adalah python atau dalam hal ini disebut dengan metode long-polling.

Berikut ini dijelaskan bagaimana untuk membuat tampilan Telegram Bot sebagai tampilan kepada pemilik rumah. Untuk pembuatannya dapat melalui aplikasi telegram pada smartphone atau melalui web Telegram, serta cara menghubungkan telegram dengan Arduino IDE.

a. Buka Telegram selanjutnya cari dan tambahkan@botfather

b. Klik Start dan akan muncul daftar perintah, klik /newbot selanjutnya akan muncul perintah untuk memberi nama bot kita. Ketik nama yang diinginkan, kemudian klik OK

c. Selanjutnya, akan muncul perintah untuk membuat username bot kita, yang harus disertai kata "bot". Kemudian copy kode angka dengan tulisan berwarna merah yang merupakan kode token API kita. Token ini yang akan menjadi acuan agar nantinya bot dapat diprogram untuk mengirimkan teks, gambar, video, dan sebagainya.

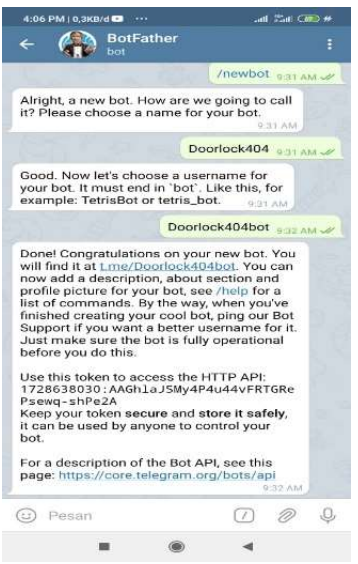

Gambar 4. Tampilan BotFather di Aplikasi Telegram

d. Setelah akun Bot telah dibuat pada telegram selanjutnya adalah menghubungkan Telegram Bot pada ESP32 dengan cara memasang library telegram pada library manager di Arduino IDE dan mengganti ChatID dan BOTtoken yang ada pada listing code.

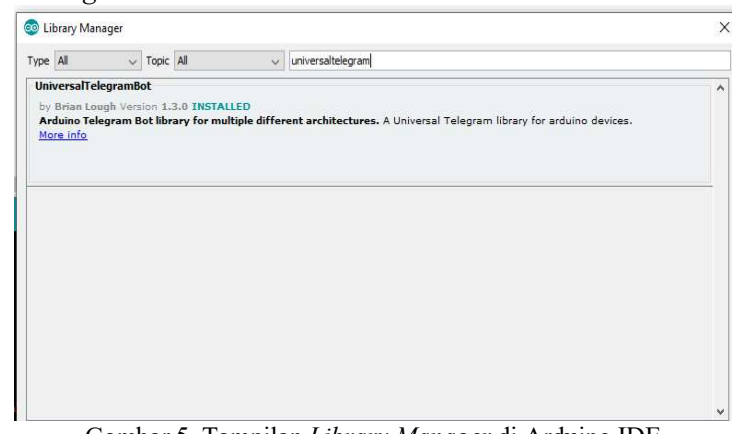

Gambar 5. Tampilan Library Manager di Arduino IDE

// Use Gmyidbot to find out the chat ID of an individual or a group

// You need to click "start" on a bot before it can message you

/ Initialize Telegram BOT

String chatId $=$ "1095677344";

String BOTtoken $=" 1728638030:$ AAGhlaJSMy4P4u44vFRTGRePsewq-shPe2A";

Gambar 6. Tampilan Listing Code ChatID dan BOTtoken di Arduino IDE

D. Cara Kerja Sistem

Cara kerja dari sistem ini adalah dengan mendeteksi wajah dan mengirimkan gambar ke Telegram. Ketika wajah yang dimasukkan benar maka akan mengaktifkan solenoid door lock yang disupply tegangan sebesar 6 Volt oleh baterai. Solenoid ini akan aktif selama 10 detik setelah itu akan menutup kembali secara otomatis dan pintu akan terkunci. Jika wajah yang dimasukkan salah maka, maka ESP32 akan memberikan informasi melalui aplikasi Telegram berupa gambar. Pada alat ini dilengkapi tombol yang berfungsi untuk mengaktifkan mode Tamu. Mode ini bertujuan untuk memudahkan membuka pintu saat ada tamu. Untuk lebih jelasnya cara kerja sistem dapat dilihat pada Gambar 7.

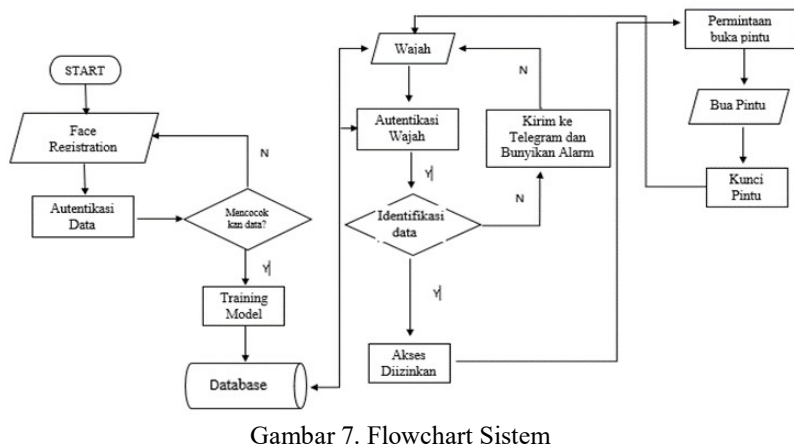

E. Model Pengujian

Pada tahap ini membahas mengenai pengujian sistem dengan mengambil data dan melakukan analisa terhadap pengujian perangkat lunak pengujian citra wajah dan delay pengiriman data terhadap Telegram. Pengujian perangkat keras dan pengujian sistem secara keseluruhan.

1) Pengujian Pengiriman Data ke Telegram

Pengujian pengiriman data ke telegram ini untuk mengetahui delay waktu ESP32 mengirimkan data ke telegram. Pengujian ini termasuk pengujian kerja alat keseluruhan karena dilakukan dari saat alat mulai mendeteksi wajah hingga akhirnya data terkirim ke telegram. Pengujian dilakukan dengan 12 data citra sampel dengan 3 citra orang berbeda, data citra tidak terdapat pada database. Pengambilan data dilakukan secara real time melalui ESP32 dengan deteksi pertama serta dilakukan pengulangan mulai sistem, dan mengurangi nilai kecocokan pada program untuk pencocokan 
saja. Untuk menghitung waktu proses pengiriman digunakan stopwatch dari awal program dijalankan sampai citra dan teks diterima oleh bot telegram.

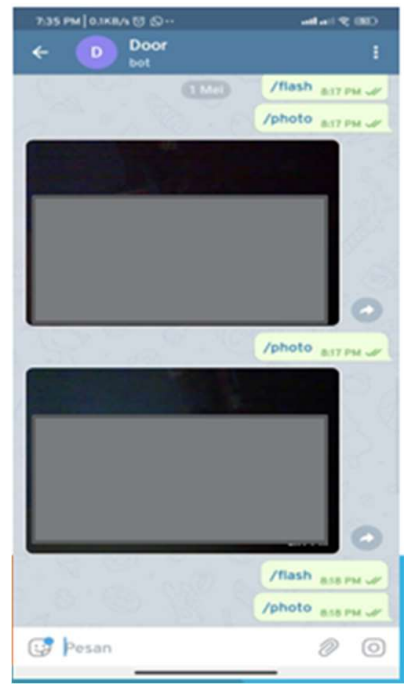

Gambar 8. Tampilan Citra Gambar yang dikirim dari Sistem ke Telegram

2) Pengujian Waktu Delay Pengendalian Relay

Pengujian dilakukan dengan mengirimkan 12 kali perintah pada telegram untuk mengendalikan relay. Untuk menghitung delay maka digunakan stopwatch pada smartphone. Hal ini dilakukan untuk menghitung berapa besara delay yang terjadi untuk telegram mengendalikan keadaan relay.

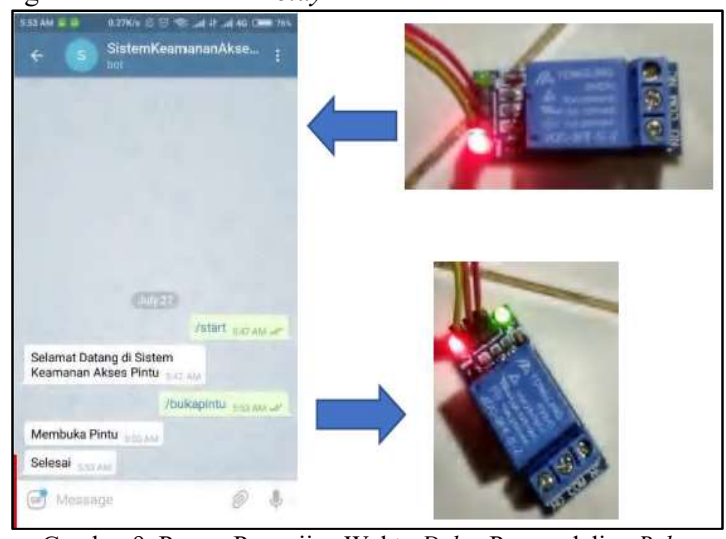

Gambar 9. Proses Pengujian Waktu Delay Pengendalian Relay

\section{HASIL DAN PEMBAHASAN}

Setelah menjelaskan rumusan metode yang akan digunakan pada bagian dua, maka hasil penelitian dan pembahasan dibagi menjadi dua, yaitu:

A. Hasil Pengujian Pengiriman Data

Pada tabel 2 dapat diketahui bahwa dari 12 citra wajah yang diuji tidak terdapat kesalahan. Sehingga keberhasilan sistem diatas berdasarkan rumus yang telah digunakan adalah $100 \%$. Dapat juga diketahui dari tabel di atas waktu delay yang dibutuhkan oleh sistem dalam pendeteksian sampai akhirnya data citra dan teks diterima oleh Telegram paling lama dengan delay 5,53 detik dan delay paling cepat yaitu 3,98 dengan rata-rata delay sebesar 4,74 detik. Hal ini disebabkan karena sistem bekerja pertama kali, maka sistem akan melakukan pelatihan dan meyimpan data ke library terlebih dahulu serta dalam melakukan pencocokan sehingga setelah proses penyimpanan dan pencocokan selesai sistem akan melakukan pengiriman data ke Telegram. Pengiriman data ke
Telegram akan dipengaruhi oleh kecepatan internet pada ESP32 serta ukuran file yang dikirimkan.

\begin{tabular}{|c|c|c|c|}
\hline \multirow{4}{*}{ Sample } & $\begin{array}{c}\text { Tabel 2. Pengujian Pengiriman Data } \\
\text { Delegram }\end{array}$ & Keterangan & $\begin{array}{c}\text { Waktu yang } \\
\text { dibutuhkan (detik) }\end{array}$ \\
\hline \multirow{4}{*}{ Aeni } & Terkirim & Berhasil & 4,50 \\
\cline { 2 - 4 } & Terkirim & Berhasil & 4,66 \\
\cline { 2 - 4 } & Terkirim & Berhasil & 4,43 \\
\cline { 2 - 4 } & Terkirim & Berhasil & 5,53 \\
\hline \multirow{4}{*}{ Indah } & Terkirim & Berhasil & 4,85 \\
\cline { 2 - 4 } & Terkirim & Berhasil & 5,22 \\
\cline { 2 - 4 } & Terkirim & Berhasil & 3,98 \\
\cline { 2 - 4 } & Terkirim & Berhasil & 4,65 \\
\hline \multirow{4}{*}{ Indri } & Terkirim & Berhasil & 4,29 \\
\cline { 2 - 4 } & Terkirim & Berhasil & 4,56 \\
\cline { 2 - 4 } & Terkirim & Berhasil & 4,89 \\
\cline { 2 - 4 } & Terkirim & Berhasil & 5,32 \\
\hline Rata-rata & waktu yang dibutuhkan & 4,74 \\
\hline
\end{tabular}

B. Hasil Pengujian Kontrol Relay

Dari hasil pengujian pada tabel 3 dapat diketahui bahwa delay pengendalian relay melalui perintah yang dikirimkan dari Telegram memiliki rata-rata delay waktu sebesar 0,81 detik. Dengan waktu delay tercepat adalah 0,4 detik dan waktu delay terlama adalah 1,3 detik. Delay Ini terjadi akibat adanya pengaruh dari kecepatan internet.

Tabel 3. Pengujian Kontrol Relay

\begin{tabular}{|c|c|c|}
\hline Pengujian & Keadaan Relay & Delay (detik) \\
\hline 1 & Menyala & 0,9 \\
\hline 2 & Menyala & 0,8 \\
\hline 3 & Menyala & 1,1 \\
\hline 4 & Menyala & 0,9 \\
\hline 5 & Menyala & 1,2 \\
\hline 6 & Menyala & 0,5 \\
\hline 7 & Menyala & 0,7 \\
\hline 8 & Menyala & 0,7 \\
\hline 9 & Menyala & 0,8 \\
\hline 10 & Menyala & 1,3 \\
\hline 11 & Menyala & 0,5 \\
\hline 12 & Menyala & 0,4 \\
\hline \multicolumn{2}{|c|}{ Rata-Rata waktu yang dibutuhkan } & 0,8 \\
\hline
\end{tabular}

\section{KESIMPULAN DAN SARAN}

A. Kesimpulan

Sistem akses pintu berhasil dibangun dengen menerapkan metode face recognition untuk meningkatkan keamanan pada pintu. Penelitian ini menggunakan bahasa pemrograman $\mathrm{C}$ dan Arduino IDE. Waktu yang dibutuhkan oleh sistem dalam pendeteksian sampai akhirnya data citra dan teks diterima oleh Telegram paling lama dengan delay 5,53 detik dan delay paling cepat yaitu 3,98 dengan rata-rata delay sebesar 4,74 detik. Hasil 
pengujian pengendalian relay melalui perintah yang dikirimkan dari Telegram memiliki rata-rata delay waktu sebesar 0,81 detik dengan waktu delay tercepat adalah 0,4 detik dan waktu delay terlama adalah 1,3 detik.

B. Saran

Untuk penelitian selanjutnya disarankan untuk mengembangkan algoritma pengiriman data dan pengontrolan relay yang lebih baik untuk memperkecil delay waktu yang dibutuhkan agar penggunaan sistem akses pintu berbasis face recognition semakin lebih baik.

\section{DAFTAR PUSTAKA}

[1] Y.-C. Yu, "A practical digital door lock for smart home," in 2018 IEEE International Conference on Consumer Electronics (ICCE), Jan. 2018, pp. 1-2, doi: 10.1109/ICCE.2018.8326305.

[2] N. A. Hussein and I. Al Mansoori, "Smart Door System for Home Security Using Raspberry pi3," in 2017 International Conference on Computer and Applications (ICCA), Sep. 2017, pp. 395-399, doi: 10.1109/COMAPP.2017.8079785.

[3] C. Vongchumyen et al., "Door lock system via web application," in 2017 International Electrical Engineering Congress (iEECON), Mar. 2017, pp. 1-4, doi: 10.1109/IEECON.2017.8075909.

[4] M. S. Hadis, E. Palantei, A. A. Ilham, and A. Hendra, "Design of smart lock system for doors with special features using bluetooth technology," in 2018 International Conference on Information and Communications Technology (ICOIACT), Mar. 2018, pp. 396-400, doi: 10.1109/ICOIACT.2018.8350767.

[5] W. A. Putra, R. Maulana, and F. Utaminingrum, "Implementasi Sistem Otomatisasi Pintu Dengan Face Recognition Menggunakan Metode Haar-Cascade Dan Local Binary Pattern Pada Raspberry Pi," J. Pengemb. Teknol. Inf. dan Ilmu Komput., vol. 2, no. 12, pp. 6997-7006, 2018.

[6] C. Lesmana, R. Lim, and L. W. Santoso, "Implementasi Face Recognition menggunakan Raspberry pi untuk akses Ruangan Pribadi,” J. Infra, vol. 7, no. 1, 2019.

[7] Rudi Kurniawan and A. Zulius, "Smart Home Security Menggunakan Face Recognition Dengan Metode Eigenface Berbasis Raspberry Pi," J. Sustain. J. Has. Penelit. dan Ind. Terap., vol. 8, no. 2, pp. 48-56, Oct. 2019, doi: 10.31629/sustainable.v8i2.1484.

[8] A. Yoke and M. Fauzi, "Perancangan Door Lock Face Recognition Dengan Metoda Eigenfaces Menggunakan Opencv2.4.9 Dan Telegram Messenger Berbasis Raspberry Pi," J. Teknol. Elektro, vol. 10, no. 1, p. 1, Dec. 2019, doi: 10.22441/jte.v10i1.001.

[9] A. Arafat, "SISTEM PENGAMANAN PINTU RUMAH BERBASIS Internet Of Things (IoT) Dengan ESP8266," $J$. Technol., vol. 7, no. 4, pp. 262-268, 2016, doi: http://dx.doi.org/10.31602/tji.v7i4.661.

[10] M. F. Wicaksono and M. D. Rahmatya, "Implementasi Arduino dan ESP32 CAM untuk Smart Home," J. Teknol. dan Inf., vol. 10, no. 1, pp. 40-51, Feb. 2020, doi: 10.34010/jati.v10i1.2836.

[11] "ESP32 Wi-Fi \& Bluetooth MCU I Espressif Systems." https://www.espressif.com/en/products/socs/esp32 (accessed Sep. 08, 2021).

[12] "OV2640: Specs, Camera, Datasheet \& Alternative (2021 Report).” https://www.arducam.com/ov2640/ (accessed Sep. 08, 2021). 